\title{
Correlations Between Macroeconomic Cycles in the US and UK: What Can a Frequency Domain Analysis Tell Us?
}

\author{
Patrick M. Crowley ${ }^{1}$ • Andrew Hughes Hallett ${ }^{2}$
}

Received: 11 March 2015 / Accepted: 31 August 2015 / Published online: 14 September 2015

(C) Società Italiana degli Economisti (Italian Economic Association) 2015

\begin{abstract}
In this paper, the relationship between the growth of GDP and real GDP components is explored in the frequency domain using both static and dynamic techniques derived from wavelet analysis. This analysis is carried out separately for the US and the UK using quarterly data, and the results are found to be quite different for both countries. One of the major findings of the paper is that there are significant relationships between cycles of the GDP components at frequencies other than the business cycle frequencies that confirm some of the predictions of economic theory; but importantly contradict others. Secondly, that the relative power of the different cycles varies over time leading to the idea of "volatility transfers" between cycles. Third that the correlations and lead-lag relationships between cycles shift over time, leading to several new insights into how the aggregate demand in these two economies has actually evolved in practice. These results are of particular significance for understanding the current weak economic recovery and for why real business cycle models do not find the right relationships between GDP components.
\end{abstract}

Keywords Business cycles - Growth cycles - Discrete wavelet analysis Time-frequency domain · US output components

JEL Classification $\quad \mathrm{C} 49 \cdot \mathrm{E} 20 \cdot \mathrm{E} 32 \cdot \mathrm{E} 60$

Andrew Hughes Hallett

ahh1@st-andrews.ac.uk

Patrick M. Crowley

patrick.crowley@tamucc.edu

1 College of Business, Texas A\&M University-Corpus Christi, 6300 Ocean Drive, Corpus Christi, TX 78418, USA

2 School of Economics and Finance, University of St Andrews, St Andrews KY16 9AL, Scotland 


\section{Introduction}

The contribution in this paper is to further analyse fluctuations in the components of US and UK growth and the interactions between the components of US and UK growth in the time-frequency domain, using multiresolution decomposition analysis and crosscorrelation analysis, thereby extending the contribution of Crowley and Hughes Hallett (2015). These interactions, to date, have not been fully explored in the time-frequency domain with the full range of data that we now have available, although probably the initial attempt to study macroeconomic data using time-frequency analysis is Gallegati and Gallegati (2007). The approach presented here can illuminate the changing relationships between GDP components at different time horizons that conventional time series analysis has difficulty identifying.

The time-frequency domain offers economists a different perspective from timeseries analysis for analysing economic data. The number of contributions in economics that use frequency domain analysis is still small, and yet a number of important advances have been made in time-frequency domain methods which have not fully filtered into the mainstream economics literature. While time-frequency domain techniques are not yet part of the standard toolbox for analysis of time series in economics, these techniques are standard in other disciplines such as engineering, acoustics, neurological sciences, physics, geology and environmental sciences.

We begin by noting the correlations for the US (1947 to 2015Q1) and the UK (19562015Q1) between the growth rates of the main components in aggregate demand in real GDP, namely personal consumption expenditures, private investment, government expenditures (both current and capital) and export of goods and services, are not that high and are often not significant and sometimes do not have the expected signs (Tables 1, 2; Crowley and Hughes Hallett 2014a).

Based on static statistics, few of the correlations are significant (- using a Fisher test, $5 \%$ significance levels are 0.119 for the US and 0.127 for the UK). Of course, this exercise ignores two important considerations: (i) that (possibly variable) lead or lag

Table 1 Correlation of US GDP components

Table 2 Correlation of UK GDP components

\begin{tabular}{lllll}
\hline & $\mathrm{C}$ & $I$ & $G$ & $X$ \\
\hline $\mathrm{C}$ & 1 & 0.627 & -0.110 & 0.079 \\
$\mathrm{I}$ & & 1 & -0.216 & 0.091 \\
$\mathrm{G}$ & & & 1 & 0.020 \\
$\mathrm{X}$ & & & & 1 \\
\hline
\end{tabular}

\begin{tabular}{lllll}
\hline & C & I & \multicolumn{1}{c}{ G } & \multicolumn{1}{c}{$X$} \\
\hline C & 1 & 0.560 & 0.114 & 0.180 \\
I & & 1 & -0.040 & 0.214 \\
G & & & 1 & -0.083 \\
X & & & & 1 \\
\hline
\end{tabular}


relationships exist and/or (ii) that (again possibly variable) cycle relationships at different frequencies might be significant between the constituent components of GDP, or within the cyclical composition of GDP, even if not in GDP as a whole. Clearly simple correlation coefficients are not going to reveal these relationships, and therefore more appropriate time-frequency domain tools are required to uncover these hidden factors.

To address these considerations we use discrete wavelet analysis to analyze the shifting (time-varying) linear relationship between the components of GDP, both in the US and UK economies, in terms of amplitude (power) in each cycle, and for inter-component correlations and lead-lag relationships.

\section{Rationale and Data}

\subsection{Rationale}

The rationale for looking at cyclical interactions between the major components of output is three-fold:

(i) there are obviously interactions between the components that occur through the business cycles-notably between consumption and investment through inventories and government policies, and between consumption and exports through the international transmission of business cycles. These interactions have policy implications;

(ii) the real business cycle literature focused on these interactions as justification for supposing technology "shocks" drive fluctuations in the economy and hence the business cycle. A deeper understanding of the interaction between the GDP components may inform model-building in terms of modelling the transmission of fluctuations or shocks better between spending units in the macro-economy; and

(iii) the cycles within GDP, or within any component of GDP, are likely to vary over time in strength and/or correlation and phase relationships with other components. This will have profound implications for policy and how well the economy performs. This paper is the first to analyse those relationships in the context of the advanced economies.

\subsection{Data}

The data used is quarterly chain-weighted quarterly real GDP data and its major components. The US data was sourced from the Bureau of Economic Analysis for 1947Q1 to 2015Q1 (giving 268 datapoints), where the data was transformed by logging the source data and then taking annual differences. The UK data was sourced from the National Statistics Office for 1954Q1 to 2015Q1 (giving 236 datapoints) and again was transformed in the same manner.

\subsection{Discrete Wavelet Analysis}

Our analytic techniques are taken from Crowley and Hughes Hallett (2014a, 2015), and then extended to allow for time varying cycles and again for between cycle and 
inter-component correlations and phase shifts. In formal terms, consider a double sequence of functions:

$$
\psi(t)=\frac{1}{\sqrt{s}} \psi\left(\frac{t-u}{s}\right)
$$

where $s$ is a sequence of scales, where scale here corresponds to a particular frequency range. The term $\frac{1}{\sqrt{s}}$ ensures that the norm of the wavelet function $\psi($.$) is equal to one.$ The function $\psi($.$) is then centered at u$ with scale $s$. In the language of wavelets, the energy of $\psi($.$) is concentrated in a neighbourhood of u$ with size proportional to $s$, so that as $s$ increases the length of support at $t$ increases. For example, when $u=0$, the support of $\psi($.$) for s=1$ is $[d,-d]$ where $2 d$ denotes the initial total width (pre-scaling) which is also known as the "tap" of the wavelet. As $s$ is increased, the support widens to $[s d,-s d]$. Dilation (i.e. changing the scale) is particularly useful in the time domain, as the choice of scale indicates the "stretching" used to represent any given variable or signal.

As projections are orthogonal, wavelets at a given scale are not affected by features of a signal at scales that require narrower support. Lastly, if a wavelet is shifted on the time line, this is referred to as translation or shift of $u$. Any series $x(t)$ can be built up as a sequence of projections onto two different sets of wavelet functions, one used to capture trend movements and cycles beyond the scale limit imposed by the researcher (the "father" wavelet), and another used to capture deviations from mean for cycles at different frequencies ("mother" wavelets). Wavelet functions are therefore indexed by both $j$, the scale, and $k$, the number of translations of the wavelet, where $k$ is often assumed to be dyadic. As shown in Bruce and Gao (1996), the wavelet coefficients can be approximated given by the integrals for father and mother wavelets as:

$$
\begin{aligned}
& s_{J, k} \approx \int x(t) \phi_{J, k}(t) d t \\
& d_{j, k} \approx \int x(t) \psi_{j, k}(t) d t
\end{aligned}
$$

respectively, where $j=1,2, \ldots J$ such that $J$ is the maximum scale sustainable with the dataset being used. Then a multiresolution representation of the signal $x(t)$ can be given by:

$$
x(t)=\sum_{k} s_{J, k} \phi_{J, k}(t)+\sum_{k} d_{J, k} \psi_{J, k}(t)+\sum_{k} d_{J-1, k} \psi_{J-1, k}(t)+\cdots+\sum_{k} d_{1, k} \psi_{1, k}(t)
$$

where the basis functions $\phi_{J, k}(t)$ and $\psi_{J, k}(t)$ are assumed to be orthogonal, that is:

$$
\begin{aligned}
& \int \phi_{J, k}(t) \phi_{J, k^{\prime}}(t)=\delta_{k, k^{\prime}} \\
& \int \psi_{J, k}(t) \phi_{J, k^{\prime}}(t)=0 \\
& \int \psi_{J, k}(t) \psi_{J^{\prime}, k^{\prime}}(t)=\delta_{k, k^{\prime}} \delta_{j, j^{\prime}}
\end{aligned}
$$


Table 3 Frequency interpretation of MRD scale levels

\begin{tabular}{ll}
\hline Scale crystals & Quarterly frequency resolution \\
\hline d1 & $2-4=6$ months- 1 year \\
d2 & $4-8=1-2$ years \\
d3 & $8-16=2-4$ years \\
d4 & $16-32=4-8$ years \\
d5 & $32-64=8-16$ years \\
d6 & $64-128=16-32$ years \\
d7 & etc \\
\hline
\end{tabular}

where $\delta_{i, j}=1$ if $i=j$ and $\delta_{i, j}=0$ if $i \neq j$. The multiresolution decomposition (MRD) of the variable or signal $x(t)$ is then given by the set of crystals:

$$
\left\{s_{J}, d_{J}, d_{J-1}, \ldots d_{1}\right\}
$$

The interpretation of the MRD using the DWT (discrete wavelet transform) described above shows the frequency range over which activity in the time series occurs. For example with a quarterly time series Table 3 shows the frequencies captured by each scale crystal.

Note that, as quarterly data is used in this study to capture the conventional business cycle length, scale crystals need to be obtained for 5 scales. This requires at least 64 observations. But to properly resolve at the longest frequency it would help to have 128 observations, and as we have at least 236 observations for all 8 series this is easily accomplished. Hence we could use either 5 or 6 crystals here, even though resolution for the d6 crystal is not high. It should be noted that if conventional business cycles are usually assumed to range from 12 quarters ( 3 years) to 32 quarters ( 8 years), then crystal $\mathrm{d} 4$ together with the $\mathrm{d} 3$ crystal should contain the business cycle.

The variance decomposition is calculated based on:

$$
E_{j}^{d}=\frac{1}{E^{d}} \sum_{k=1}^{\frac{n}{2^{j}}} d_{j, k}^{2}
$$

where $E^{d}=\sum_{j} E_{j}^{d}$ represents the energy in each of the $j$ detail crystals.

Although extremely popular due to its intuitive approach, the DWT suffers from two drawbacks: the dyadic length requirements for the series to be transformed and the fact that the DWT is non-shift invariant. In order to address these two drawbacks, the maximal-overlap DWT (MODWT) ${ }^{1}$ was originally introduced by Shensa (1992), and a phase-corrected version was added and found superior to other methods of

\footnotetext{
1 As Percival and Walden (2000) note, the MODWT is also commonly referred to by other names in the wavelet literature such as non-decimated DWT, time-invariant DWT, undecimated DWT, translationinvariant DWT and stationary DWT. The term "maximal overlap" comes from its relationship with the literature on the Allan variance (the variation of time-keeping by atomic clocks)—see Greenhall (1991).
} 
frequency decomposition ${ }^{2}$ by Walden and Cristan (1998). The MODWT gives up the orthogonality property of the DWT to gain other features, given in Percival and Mofjeld (1997) as the ability to handle any sample size regardless of whether the series is dyadic or not, increased resolution at coarser scales as the MODWT oversamples the data, translation-invariance, and a more asymptotically efficient wavelet variance estimator than the DWT.

The first real usage of wavelet analysis in economics was by James Ramsey and can be found in Ramsey and Lampart (1997), and the first application of wavelets to economic growth (in the form of industrial production) was by Gallegati and Gallegati (2007) and in the form of GDP in a working paper by Crowley and Lee (2005) and then more recently in Yogo (2008) and Crowley and Hughes Hallett (2015). Reviews of wavelet analysis specifically for economists can be found in Gençay et al. (2001), Crowley (2007) and Ramsey (2008).

Lastly, in this paper the wavelet basis functions used are Daubechies tap-4 wavelet filters, with a reflective boundary assumption, and then a "brick wall" boundary assumption is used in order to derive the wavelet correlations.

\section{Results: A Univariate Cyclical Analysis}

In this section we review the output from the MODWT for both US and UK real GDP and their aggregate demand components.

\subsection{MODWT: US Data}

Figure 1 shows the original data (in the first row), together with the phase-adjusted crystals for each of the detail crystals "d1" to "d6", plus the smooth (the residual from the series having extracted the frequencies corresponding to the detail crystals, denoted as "s6"). The most obvious observation is that the "great moderation" clearly appears in the data from 1983 through to the end (2015), although a brief departure in 2009-2011 appears during the financial crisis and great recession. After 2011, the moderation reappears in the $\mathrm{d} 1, \mathrm{~d} 2$ and $\mathrm{d} 3$ crystals (i.e. for cycles between 6 months and 4 years periodicity), but less so in the 4-8 years cycle (d4 crystal) and not at all in the 8-16 years cycle (d5 crystal). There also appears to be the possibility of a longer 30 -year cycle in the data, which appears here in s6, the "smooth". Figure 6 shows the variance decomposition by crystal over the entire data span, and clearly the strongest cycle is contained in crystal d3 (representing 2-4 year cycles), with d4 (representing 4-8 year cycles) following close behind, then $\mathrm{d} 2$ ( $1-2$ years) and $\mathrm{d} 5$ (8-16 year cycles) contain roughly the same amount of energy. As noted before though, the amount of volatility in any given crystal can change over time. So during the "great moderation", crystals d4, d5 and d6 (4-32 year cycles) appear to dominate fluctuations in growth, but not necessarily during other periods: a volatility shift.

$\overline{2 \text { The MODWT was found superior to both the cosine packet transform }}$ and the short-time Fourier transform. 


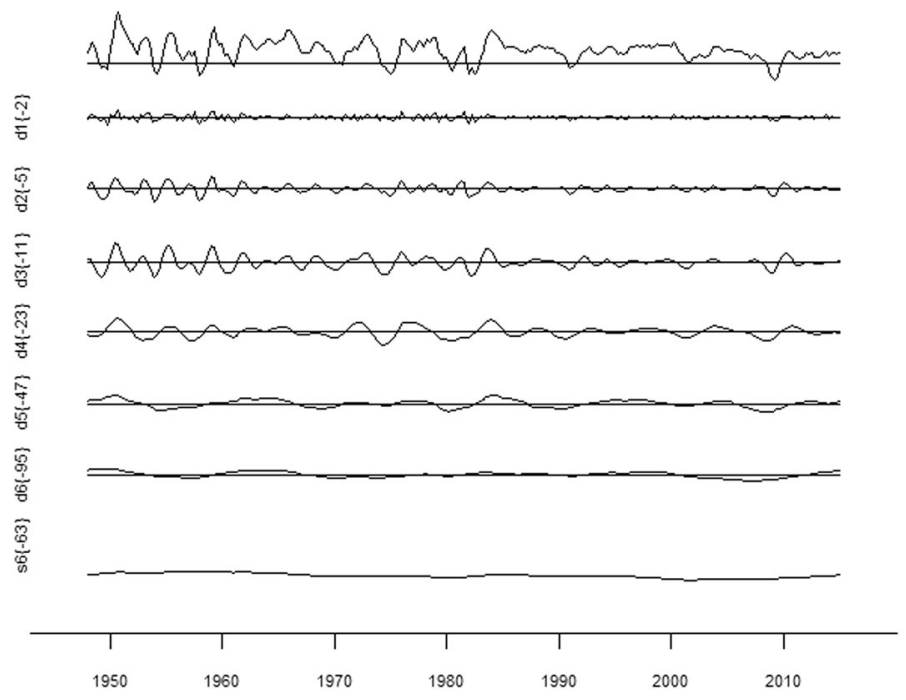

Fig. 1 MODWT decomposition of log change in US real GDP

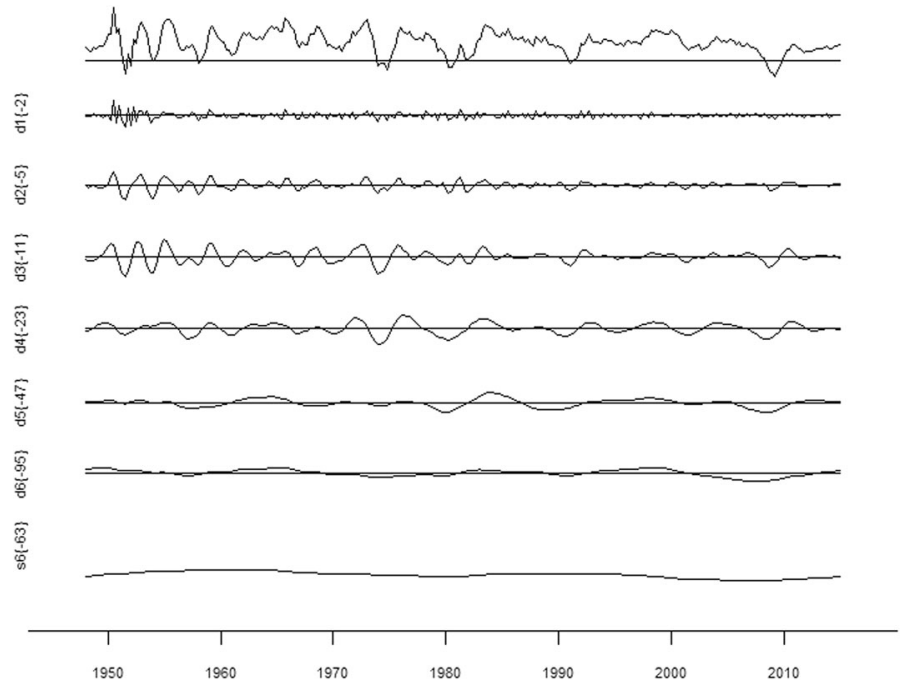

Fig. 2 MODWT decomposition of log change in US real consumption growth

As might be expected, the MODWT plot in Fig. 2 for consumption expenditures shows relatively similar cyclical patterns to overall GDP, with a clear fall in volatility after 1983 in crystal d3 (2-4 years cycles) but less so for d1, d2 or d4. This is also reflected in the energy decomposition plot in Fig. 6 where there is now relatively more volatility in longer cycles representing the effect of consumption smoothing over time.

Figure 3 shows the MODWT plot for US private investment, and it is clearly apparent that the "great moderation" in investment spending took place after around 1987, later than in consumption, and again was mostly confined to fluctuations in $\mathrm{d} 2$ and 


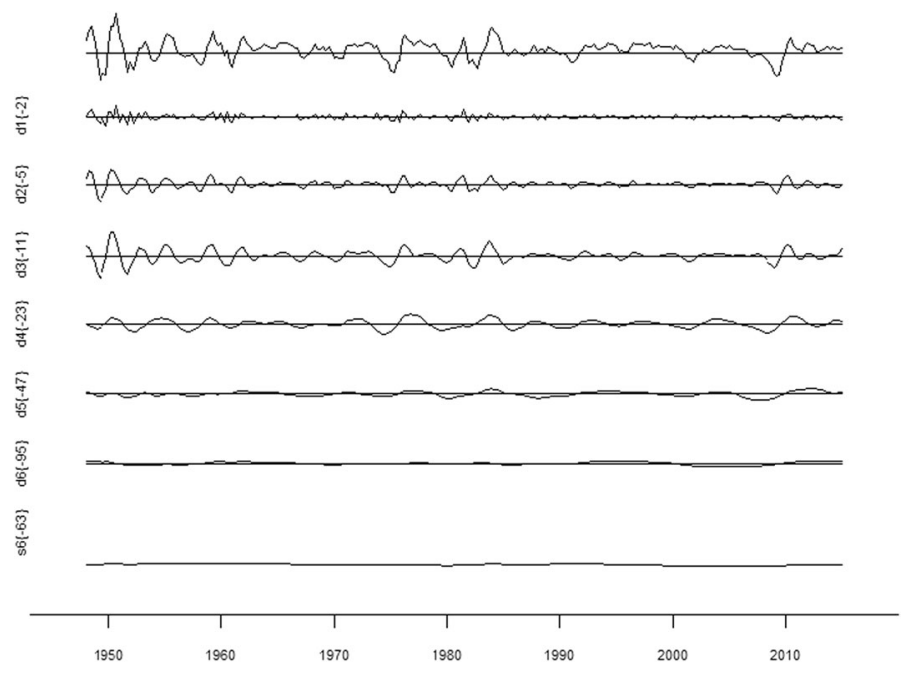

Fig. 3 MODWT decomposition of log change in US real private investment growth

$\mathrm{d} 3$ crystals, but not in $\mathrm{d} 4$ and $\mathrm{d} 5$, and hardly at all in $\mathrm{d} 1$. In terms of overall energy, the variance decomposition plot in Fig. 6 shows that most energy lies in crystal $\mathrm{d} 3$ (2-4 year cycles), with both $\mathrm{d} 2$ (1-2 year cycles) and d4 (4-8 year cycles) containing some cyclical activity. In the case of $\mathrm{d} 2$ this energy mostly occurred towards the beginning of the time series, whereas with $\mathrm{d} 4$ this appears to have been more consistent through time and likely relates to the business cycle.

Government expenditures, as they contain both automatic stabilizers and for more severe recessions anti-cyclical discretionary spending programs, should display some cyclical activity, particularly at business cycle frequencies. Figure 4 shows that apart from the very beginning of the series, there is relatively little cyclicality in the series, and where there is, this clearly lies at around the business cycle in crystals d3, d4 and d5 (2-16 year cycles). Compared to the other components of GDP the volatility in the crystals is extremely weak, signifying the relatively minor movements in government expenditures compared to private sector activity. Interestingly there is virtually no energy at short term horizons (6 month to 1 year cycles) and activity in other crystals dies down to very small fluctuations after the mid-1970s, perhaps indicating the abandonment of discretionary fiscal policies. These results are also reflected in the variance decomposition by scale which is shown in Fig. 6 where crystals d4 and d5 have the highest variance.

The MODWT plot shown in Fig. 5 for exports is rather surprising. It shows a clear reduction in volatility for crystal d1 from around the mid-1970s with a reduction in volatility in crystal $\mathrm{d} 2$ in roughly 1983 , followed by reductions in volatility in $\mathrm{d} 3$ and d4 in the late 1980s. Volatility then picks up again for crystals d2, d3, d4 and d5 in the late 1990s and continues into the 2000s, with the exception of the d1 crystal, which shows hardly any short-term movements. Figure 6 shows that most of the energy in the series resides in crystals $\mathrm{d} 3$ and $\mathrm{d} 4$, with cycle frequencies between 2 and 8 years, corresponding to the business cycle. 


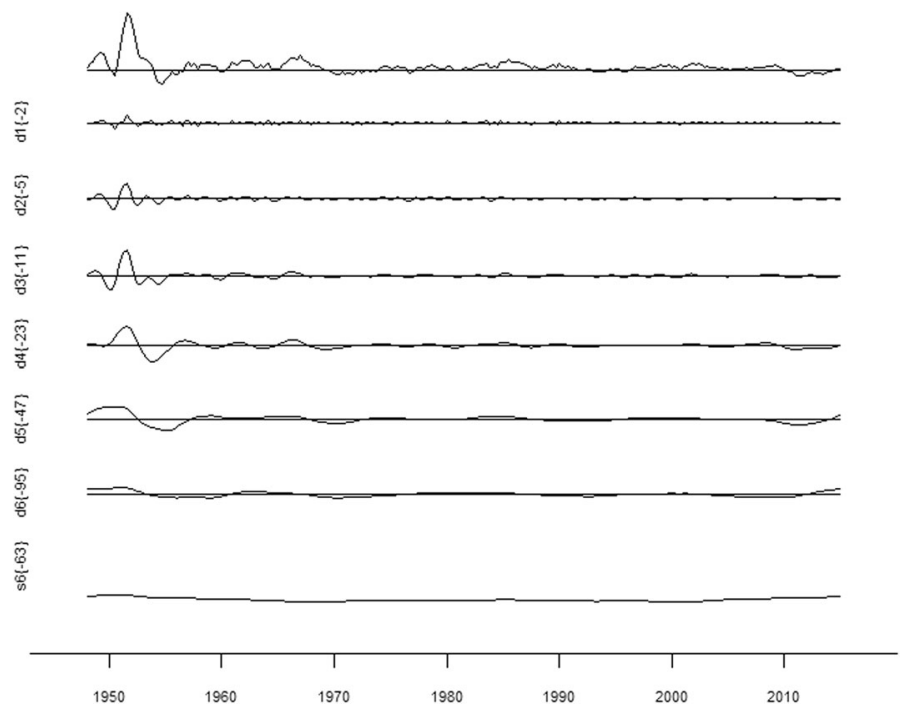

Fig. 4 MODWT decomposition of log change in US real G growth

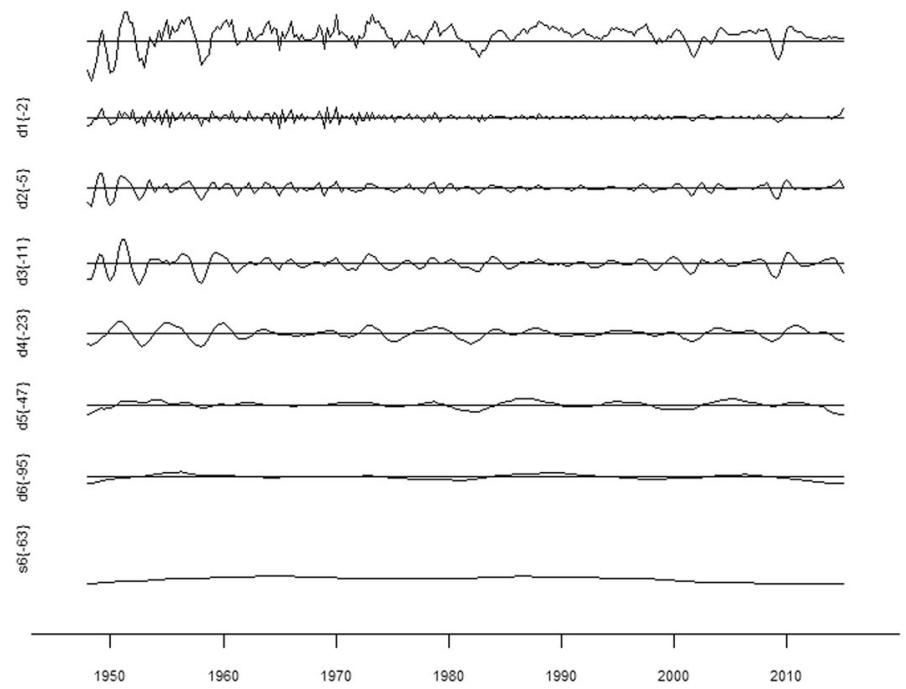

Fig. 5 MODWT decomposition of log change in US real export growth

To summarize, for the US, it is clear that the "great moderation", although apparent in GDP growth data, is also apparent at various frequencies and in various components of GDP. But the timing and dynamics that lead to the "great moderation" are not directly translated back to the components of GDP growth. Consumption and investment appear to be the sources for the "great moderation" with consumption volatility moderation occurring in the early 1980s and investment volatility moderation occur- 

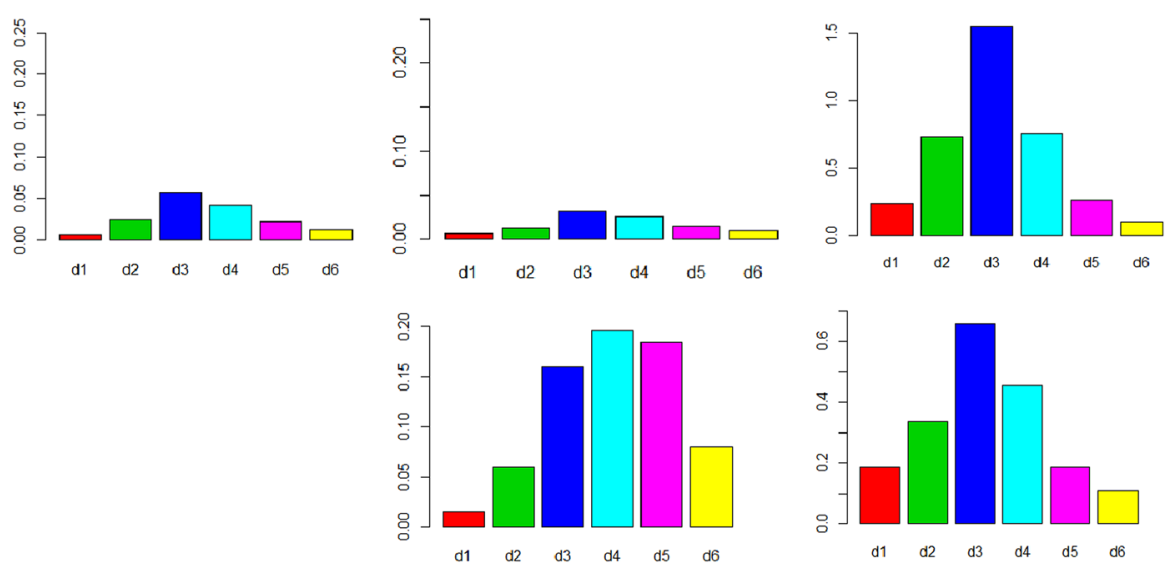

Fig. 6 US energy distribution by wavelet crystal. First row Y, C, I, second row G, X

ring in the later part of the 1980s. Changes in government expenditure and export expenditures do not appear to be major sources of lower volatility in real GDP growth.

\subsection{Cyclical Complexity: Is There More Than One Great Moderation Period in Our Sample?}

At this point, it is reasonable to ask if our analysis of cyclical volatility does not reveal a more complex pattern than that highlighted in the previous section. This question is prompted by the results of Gallegati and Gallegati (2007) who find evidence of two periods of moderation in our sample period: from the mid-1960s to 1970s; and then again from the later 1980s till mid-2000s.

Do we find this earlier period of moderation in our results, and is it a general feature in all cycles, GDP components and in both countries? Or is it feature that appears only in some cycles and components (hence only in certain parts of the economy), and specific to certain economies?

To some extent, we do find earlier periods of moderation in certain variables in the US; but not in the UK data (see the discussion in Sect. 3.4 below which highlights the differences with the US results). So we conclude that it is not a general phenomenon. The point of picking out this aspect of our results is that it shows how finely we can dissect the cyclical movements in, and interactions between, specific variables in the economy by extending the Gallegati and Gallegati approach.

In the US results, we find no real evidence of moderation before 1980, except perhaps in the $\mathrm{d} 2, \mathrm{~d} 3$ and $\mathrm{d} 4$ frequencies (business cycles from 3 to 8 years) over the interval 1965-1973. But we do find it more clearly in consumption and investment in that interval, albeit offset by less moderation in government spending and exports. That would reflect the policies of the age; greater interventions (the Great Society and Vietnam War programs), and the failures and final withdrawal of the stabilizing restrictions of the Bretton Woods regime respectively. So perhaps a better interpretation would be that we see less of an increased moderation in this earlier period, more a 


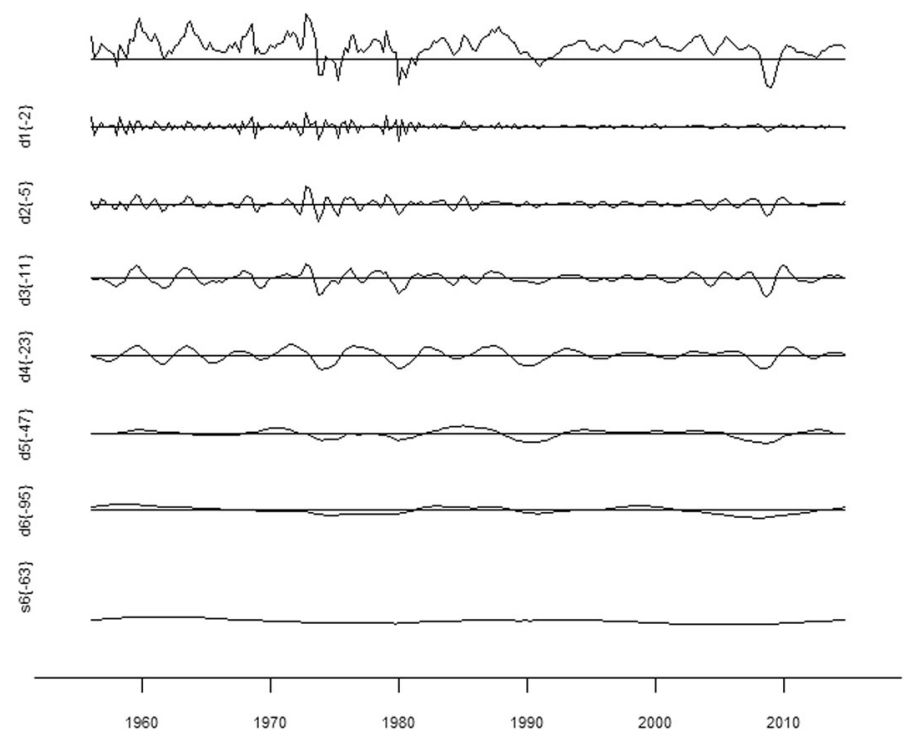

Fig. 7 MODWT decomposition of log change in UK real GDP growth

lull before the disruptions at business cycle frequencies in the Carter and first Reagan periods.

\subsection{MODWT: UK Data}

The same exercise is now repeated for the UK. In Fig. 7 we observe the same patterns as for US GDP, with crystals d1, d2 and d3 exhibiting lower volatility after 1984 but with $\mathrm{d} 4$ exhibiting only slightly lower volatility and d5 and d6 hardly changing. But that moderation is lost again and with a vengeance, at least in $\mathrm{d} 2, \mathrm{~d} 3$ and $\mathrm{d} 4$, in 2007-2008 - possibly quietening down again after 2012. The longer residual cycle is once again weak, and has a periodicity of approximately 35 years. Figure 12 shows that most of the variance resides in $\mathrm{d} 3, \mathrm{~d} 4$ and $\mathrm{d} 5$ (2-16 years periodicities), with $\mathrm{d} 4$ (4-8 years cycles) containing the greatest amount of energy.

In sum, the main moderation in the UK economy as a whole has been post 1990 until 2007, when the effects of the great recession are clear to see. This is true in all the component cycles too.

In Figs. 8 and 12 the MODWT and the variance decomposition by scale are shown for UK consumption growth. In Fig. 8 the "great moderation" is evident from 1983 in d1, but doesn't occur until roughly 1991 in d2 and d3, and not until roughly 1995 in d4. In terms of volatility, d4 and d5 clearly have most energy; and although d4 has been less volatile until the recent downturn, d5 has not. Another cycle appears to also have emerged since the mid-1970s in the d6 crystal with roughly a 16 year periodicity. There appears to be little cyclicality beyond this frequency.

In Fig. 9 the change in UK private investment expenditures are decomposed using the MODWT, and here much more cyclicality is detected than with the US, with only 


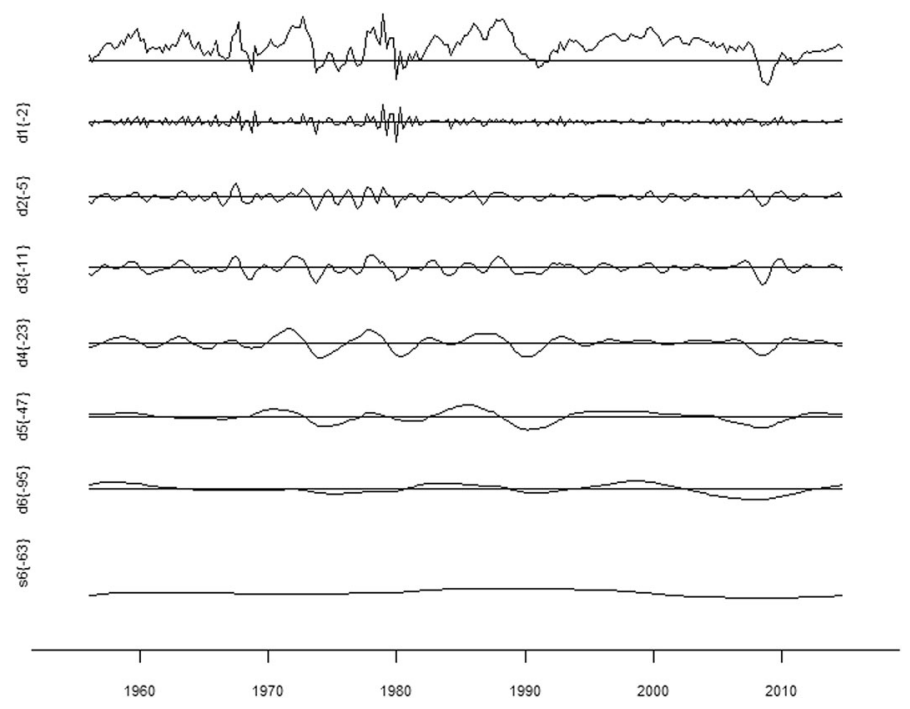

Fig. 8 MODWT decomposition of log change in UK consumption growth

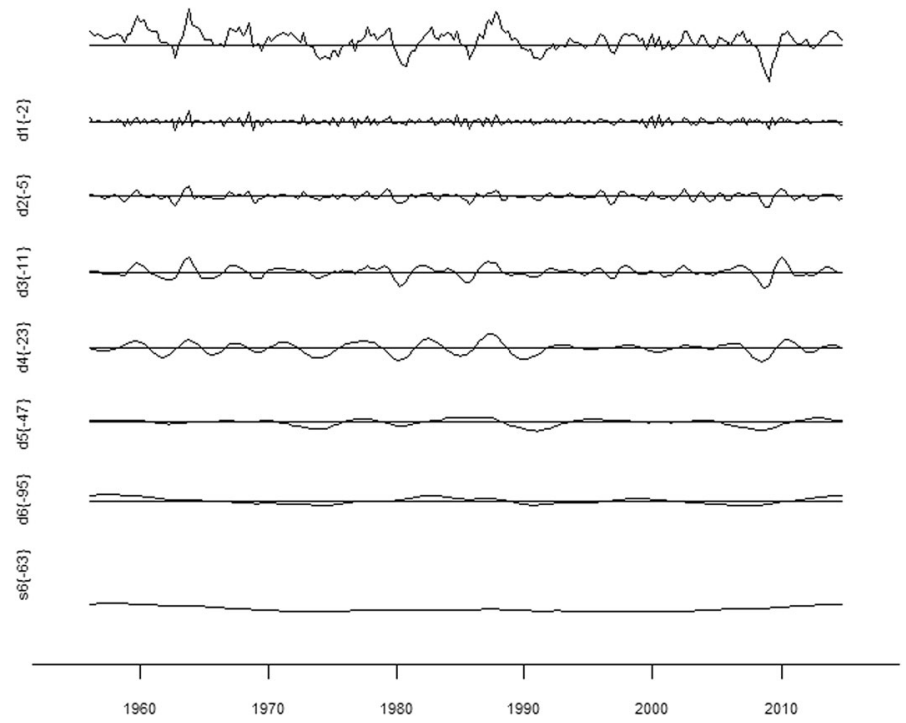

Fig. 9 MODWT decomposition of log change in UK real investment growth

two of the crystals, d1 and d4, exhibiting any real lowering of volatility, and then only after 1990. This is a surprising result, and does not match those obtained for the US. In Fig. 12 most of the volatility lies in crystals $\mathrm{d} 3$ and $\mathrm{d} 4$, and possibly a recent increase in volatility in $\mathrm{d} 5$, perhaps reflecting a lengthening of the business cycle.

With UK government expenditures, there is also much more volatility than with the US measure, as Fig. 10 shows. Here there appears to have been a dampening of volatility in the overall series only after 1975-1976 when the UK had to arrange a bail- 


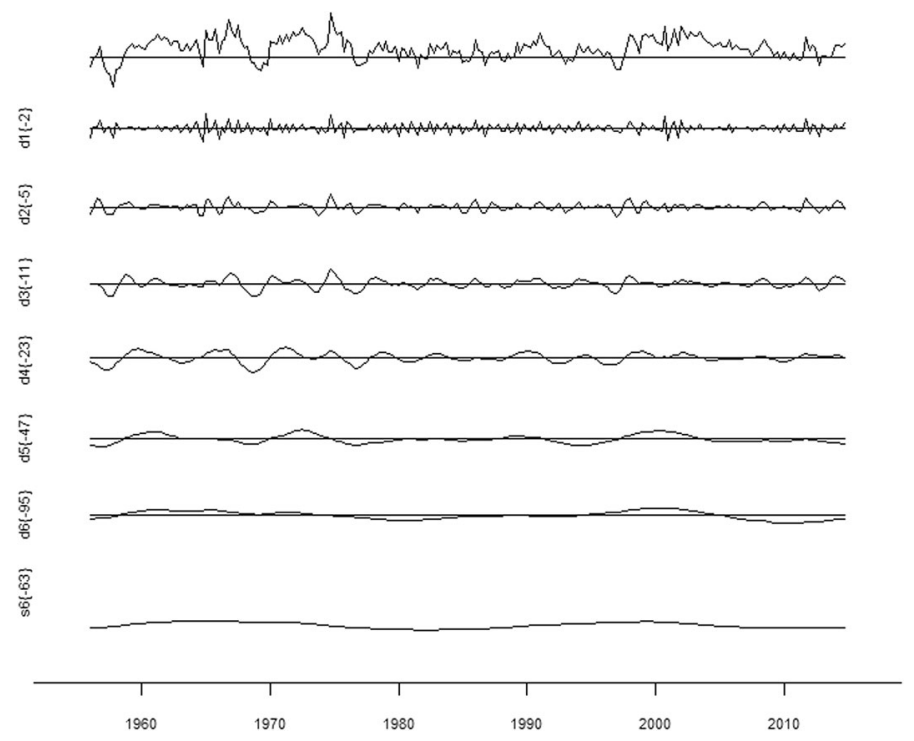

Fig. 10 MODWT decomposition of log change in UK real government spending growth

out from the IMF, after a period of strikes and increased fiscal activity of the Heath government which is clearly shown in 1970-1973. The comparative calm following the bail-out lasted through the Thatcher reforms and beyond, although the recession that resulted in the EMS crisis of 1992-1993 is clear to see. Fiscal activity picked up sharply with the Blair government in 1997, and remained until 2015 with some extra activity in 2007 and 2011. Among the component cycles, d1 (short run cycles) dampened in the mid-1990s while d2 and d 3 appeared to supply the increased activity and power of the Blair regime, at a time when monetary policy became formally independent and fiscal policy started to be much more closely managed. Cycles do appear to operate at lower frequencies as well, with increased power in the d5 and d6 crystals from the mid 1990s - that is, from the heyday of the great moderation period. Figure 12 shows that most energy resides in the $\mathrm{d} 3$ and $\mathrm{d} 4$ crystals, but a significant amount of movement is found in $\mathrm{d} 1$, which may contain noise as much as very short cycles.

In Figs. 11 and 12 the MODWT decomposition of expenditures on UK exports is plotted together with the variance decomposition by crystal. Here, there are two episodes of high volatility in export expenditures, presumably in this instance mostly related to the fortunes of the British currency. After the 1964 and 1976 devaluations of the pound there is clearly greater volatility in export growth, which lasts until the structural reforms of the early 1980s. This then continues through the collapse of Bretton Woods in 1973. Much smaller fluctuations are observed in d1 to d3 (and to a lesser extent in d4) after 1987, but by 2005 volatility in export expenditures has clearly returned in all cycles up to $\mathrm{d} 4$. On the other hand $\mathrm{d} 5$ appears to suggest that a regular 10 year cycle has emerged and d6 suggests a weak cycle at roughly a 27 year periodicity These are long cycles. Figure 12 shows that higher frequency cycles (with 


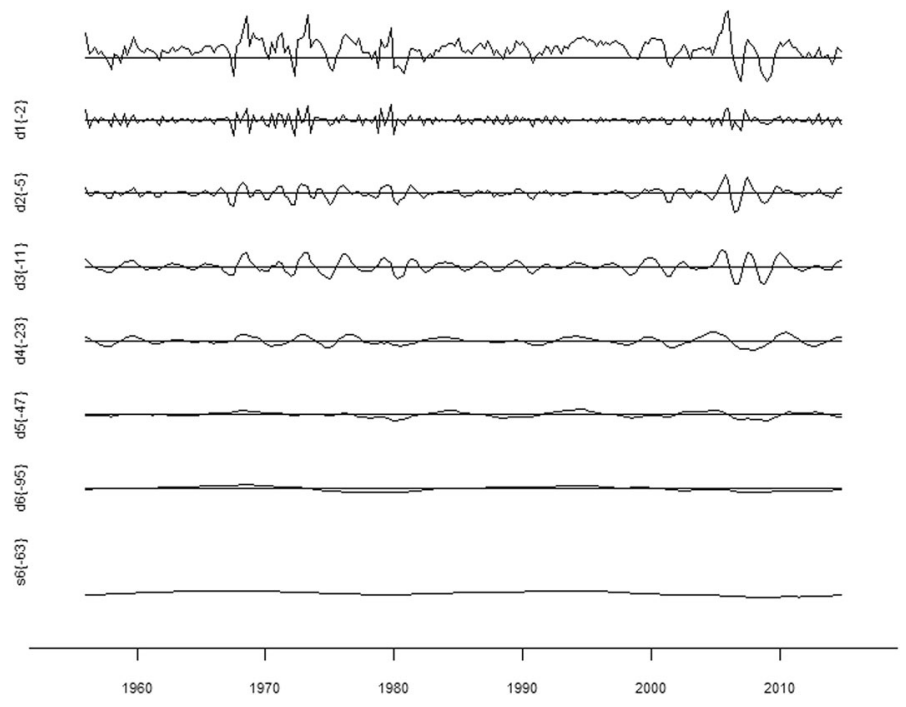

Fig. 11 MODWT decomposition of log change in UK real export growth
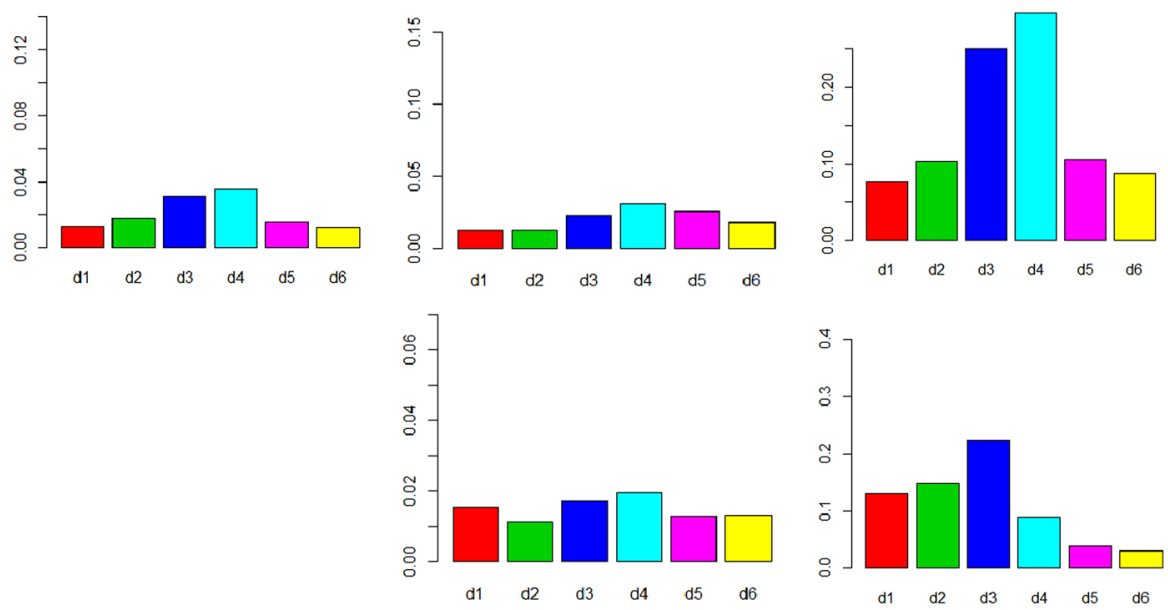

Fig. 12 UK energy distribution by wavelet crystal. First row Y, C, I, second row G, X

periodicity less than 4 years) dominate the variance decomposition in this caseonce again, quite a different result from that obtained for the US, where the "great moderation" is evident.

\subsection{Earlier Moderations in the UK?}

To make the contrast with the US results stand out, we find no evidence at all of an earlier period of moderation in the UK data. On the contrary, what we see here that there was increasing volatility and instability from the time of the return of a 
weak Labour government in 1974 to the end of the first Thatcher administration in 1982. Once again this will be policy based and reflects changes in behavior at the time (inflation, rising unemployment, "the winter of discontent", before a new era of economic and monetary management was ushered in), rather than the regularities of the underlying economy. The power of these techniques is that they allow us to dissect the movements, inter-actions and impact of policy changes in some detail.

\section{A Dynamic Correlation Analysis}

Given that wavelet analysis can decompose a series into sets of crystals at various scales, it is not such a big leap to take each scale crystal and use it as a basis for decomposing the variance of a given series into variances at different scales. Here we follow a simplified version due to Constantine and Percival (2003) which is originally based on Whitcher et al. (2000) (with full-blown mathematical background provided in Whitcher et al. (1999)). Other more technical sources for this material are Percival and Walden (2000) and Gençay et al. (2001).

Let $x_{t}$ be a (stationary or non-stationary) stochastic process, then the time-varying wavelet variance is given by:

$$
\sigma_{x, t}^{2}\left(\lambda_{j}\right)=\frac{1}{2 \lambda_{j}} V\left(w_{j, t}\right)
$$

where $\lambda_{j}$ represents the $j$ th scale level, and $w_{j, t}$ is the $j$ th crystal. The main complication here comes from making the wavelet variance time independent, the calculation of the variance for different scale levels (because of boundary problems) and accounting for when decimation occurs. For ease of exposition, assume we are dealing with an MODWT, and assume that a finite, time-independent wavelet variance exists, then we can write Eq. 8 as:

$$
\tilde{\sigma}_{x, t}^{2}\left(\lambda_{j}\right)=\frac{1}{M_{j}} \sum_{t=L_{j}-1}^{N-1} d_{j, t}^{2}
$$

where $M_{j}$ is the number of crystal coefficients left once the boundary coefficients have been discarded. If $L_{j}$ is the width of the wavelet (filter) used at scale $j$, then we can calculate $M_{j}$ as $\left(N-L_{j}+1\right)$.

Calculation of confidence intervals is a little more tricky. Here the approach is to first assume that $d_{j} \sim \operatorname{iid}\left(0, \widetilde{\sigma}_{j}^{2}\right)$ with a Gaussian distribution, so that the sum of squares of $d_{j}$ is distributed as $\kappa \chi_{\eta}^{2}$, and then to approximate what the distribution would look like if the $d_{j}$ are correlated with each other (- as they are likely to be). This is done by approximating $\eta$ so that the random variable $\left(\sigma_{x, t}^{2} \chi_{\eta}^{2}\right) / \eta$ has the same variance as $\tilde{\sigma}_{x, t}^{2}$-hence $\eta$ is not an actual degrees of freedom parameter, but rather is known as an "equivalent degrees of freedom" or EDOF. There are three ways of estimating the EDOF in the literature, and these can be summarised as (i) based on 
large sample theory, (ii) based on a priori knowledge of the spectral density function and (iii) based on a band-pass approximation. ${ }^{3}$

Once the wavelet variance has been derived, the covariance between two economic series follows, as shown by Whitcher et al. (2000). The covariance of the series can be decomposed by scale, and thus different "phases" between the series can be detected. Once covariance by scale has been obtained, the wavelet variances and covariances can be used together to obtain scale correlations between series. Once again, confidence intervals can be derived for the correlation coefficients by scale (these are also derived in Whitcher et al. (2000)).

\subsection{US}

The wavelet (crystal) correlations for the US are shown in black, together with the cocorrelations in Figs. 13 and 14. Here 90\% confidence intervals are used, and indicated in blue for the contemporaneous correlations and in red for the co-correlations. If the lower confidence interval is greater than zero then the wavelet correlation is positively significant (and of course vice-versa if the correlation is negative). The scale is given according to multiples of the Nyquist frequency, ${ }^{4}$ which here is the lower bound on the $\mathrm{d} 1$ crystal, in other words 6 months, and so wavelet scale of 2 should be interpreted as the $\mathrm{d} 2$ crystal etc.

Figure 13 (upper left hand plot) shows that the contemporaneous wavelet correlations between the $\mathrm{d} 2, \mathrm{~d} 3, \mathrm{~d} 4$ and $\mathrm{d} 5$ crystals of consumption and investment are around 0.5 , or above, and significant. This corresponds to significant correlations between cycle lengths from 1 to 16 years. Interestingly the $\mathrm{d} 1$ crystals are negatively and significantly correlated, implying that the short-run cycles are negatively correlated (likely due to inventory effects), and the d6 correlations are positive but not significant. ${ }^{5}$

Figure 14 (upper left hand plot) shows lead and lag correlations for C versus I, and suggests that the relationship between $\mathrm{C}$ and $\mathrm{I}$ is complex. Reading from left to right, the different crystal co-correlations are shown (—scale here refers to crystal), and the vertical lines through each plot refer to the contemporaneous correlations and essentially provide the results just plotted in Fig. 13. On the horizontal axis, correlations to the left of the vertical line at zero show the co-correlations when $\mathrm{C}$ leads I, and correlations to the right of the vertical line show co-correlations when C lags I. Figure 14 shows that for many of the crystals there are significantly positive and negative correlations where $\mathrm{C}$ both leads and lags I. For example for the $\mathrm{d} 2$ crystals, the contemporaneous correlation is significantly positive, but in fact the largest correlations are where $\mathrm{C}$ lags I by 4 quarters to 8 quarters, and (less so) where it leads I by $4-8$ quarters. In other words, when $C$ lags I, consumption spending adjusts fairly

\footnotetext{
${ }^{3}$ Note also that Gençay et al. (2001) show that if $d_{j}$ is not Gaussian distributed then by maintaining this assumption this can lead to narrower confidence intervals than should be the case.

${ }^{4}$ The Nyquist frequency refers to the highest frequency that can be detected given the sampling frequency of the data.

5 None of the d6 crystal correlations are significant, as accounting for boundary effects, there is insufficient data to calculate confidence intervals.
} 

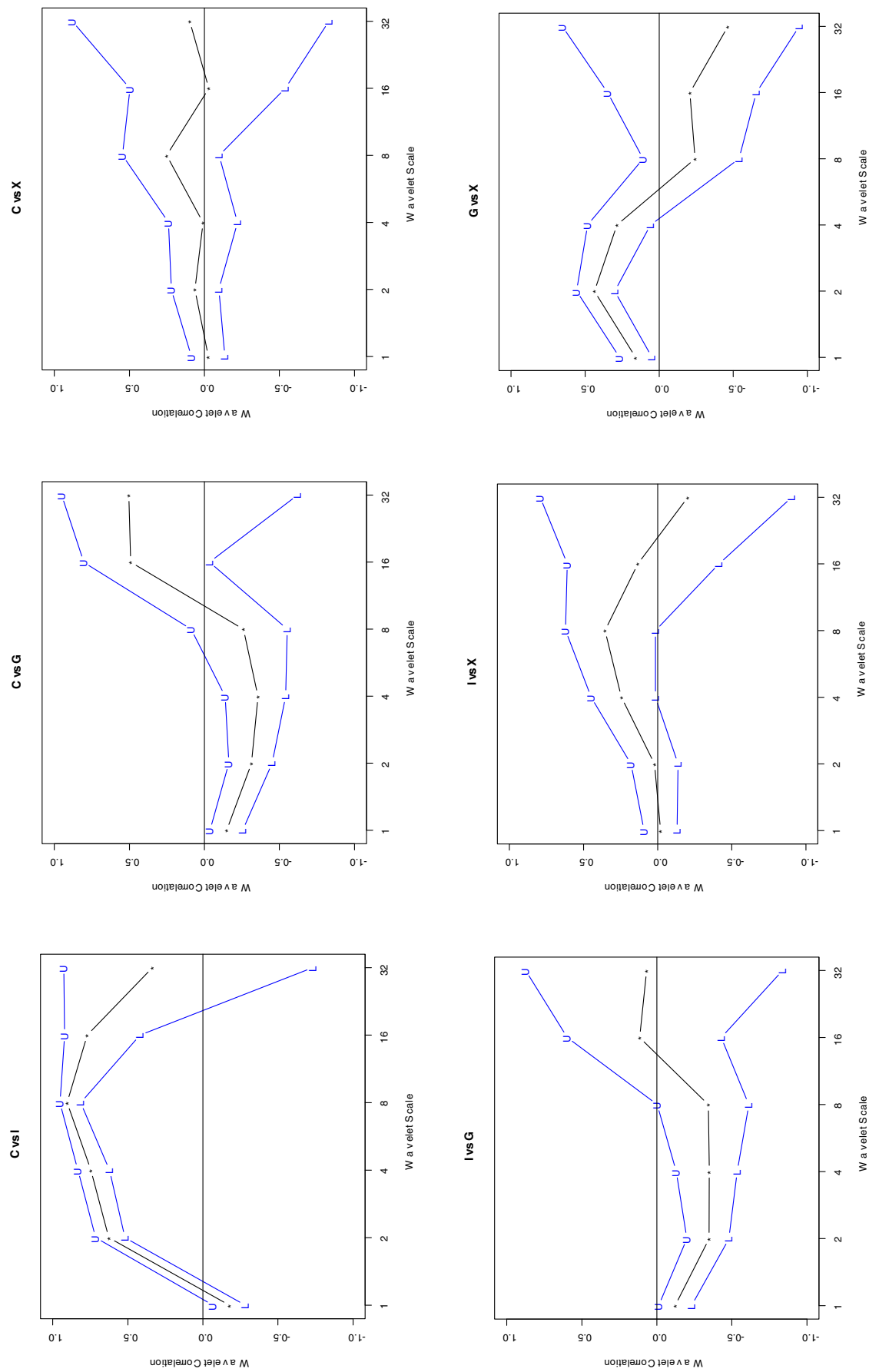

0
0
0
0
0
0
0
0
0
0
0
3
0
0
0
0
0
0
0
0
0
0
0
0
0
0
0
0 

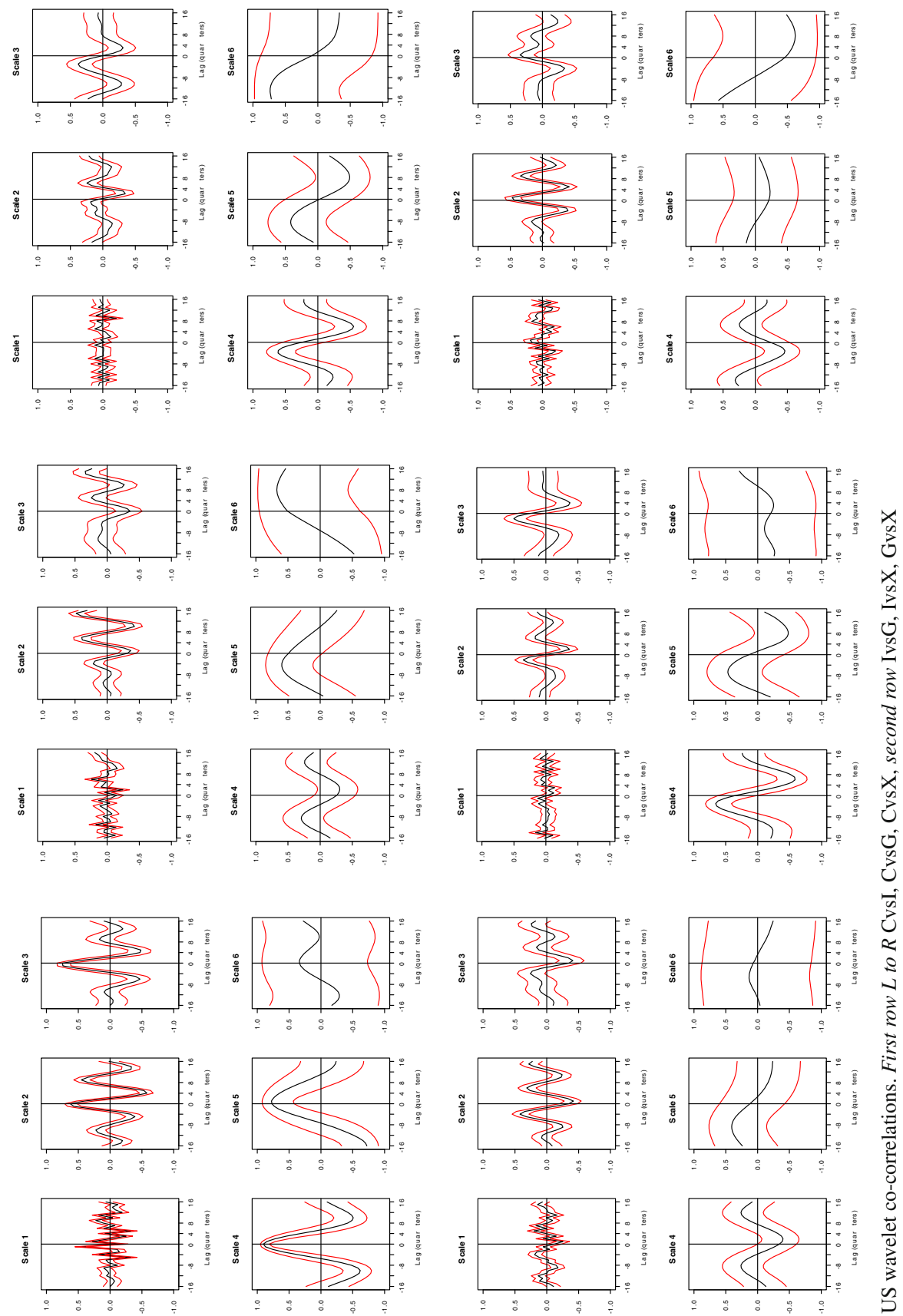
rapidly to changes in aggregate spending caused by changes in investment (investment may have increased in anticipation of increased economic activity). But when $\mathrm{C}$ leads, investment adjusts to match the changes in aggregate spending in the short term, but moves in the opposite direction in the longer term-a classic accelerator effect after the necessary investment has been undertaken.

Given the periodicity detected by wavelet analysis at this frequency (1-2 years) this is as might be expected. For example, for $\mathrm{d} 1$, there are no correlations. For $\mathrm{d} 2$, cycles up to 2 years in length, the largest correlation is positive with a lead of $\mathrm{C}$ over I of perhaps one quarter, then 4 quarter leads and lags give negative correlations, then 8 quarter leads and lags a significant positive correlation, and then no further significant correlations as $\mathrm{C}$ leads or lags I by increasing amounts. Then $\mathrm{d} 3$, short business cycles of 2-4 years in length, there are no correlations at any leads or lags; and for $\mathrm{d} 4$, longer business cycles up to 8 years in length, there are negative correlations at 6 quarter leads and lags.

Clearly overall $\mathrm{C}$ tends to lag I more than lead it, as seen from the size of the correlations between individual cycles, although for the longer cycles (d4 and up) this effect fades: the larger correlations are then contemporaneous. This is as we might expect: we are reinforcing the accelerator effect noted two paragraphs earlier, but then watching it equalise out with the passage of time over longer cycles. What is interesting here is that most of the time C lags I in the US, but of course this might not be always the case elsewhere. Also it is interesting that this effect doesn't just occur at business cycle frequencies-it clearly also occurs at shorter growth cycle frequencies as well.

Figure 13 (upper row, middle plot) shows the contemporaneous correlations for $\mathrm{C}$ vs $\mathrm{G}$; and perhaps as expected, $\mathrm{d} 1, \mathrm{~d} 2$ and $\mathrm{d} 3$ are negatively correlated, but $\mathrm{d} 4$, while still negative, is not significant and d5 and d6 are positive, but not significant. Countercyclical fiscal policy (consumption smoothing) is evident in the short run (up to 4 years), but has no significant association with longer run developments such as long business cycles and beyond. No countercyclical policy would ever be expected to fully offset changes in $\mathrm{C}$ as multiplier effects are usually found to fade away to zero after a few years. So it is to be expected that not all wavelet correlations would be significant. In Fig. 14 what is interesting is whether the automatic stabilizers dominate any one-time fiscal policy actions - in other words whether C leads G or lags G. Clearly in current economic circumstances $\mathrm{C}$ would be expected to lag $\mathrm{G}$, but at other times $\mathrm{C}$ could lead $\mathrm{G}$ as increased taxes might lead to increased $\mathrm{G}$. At the $1-4$ year cycle frequencies ( $\mathrm{d} 2$ and $\mathrm{d} 3$ ), there is clear evidence that co-correlations are higher and significant when $C$ lags $G$ (—in other words when $G$ acts to stimulate C)-and they appear to be particularly significant at at the 5 quarter and 10 quarter lags, but with a possible reversal at 8 quarters in between. But after 8 year cycles there are no more leads or lags; fiscal stimulus policies are played out.

In Fig. 13 (upper row, right hand plot) there is very little contemporaneous relationship between $\mathrm{C}$ and $\mathrm{X}$, which is as expected. As Fig. 14 (upper row, right hand plot) shows, however, there is a likely to be a "lead" relationship between C and X as it is widely acknowledged that US consumers have been the main driver behind global growth in recent decades. When looking at short time horizons, say 1 to 2 year cycles, US C lags X by about 4 quarters (perhaps representing international spillover effects from other countries), but when looking at longer time horizons, from 4 to 16 
year cycles, it is apparent that $\mathrm{C}$ leads $\mathrm{X}$ by 4-8 quarters, and because these are cycles, there is also a lagged effect by roughly the same amount. But, as one might expect, these lead/lag effects eventually merge and become unclear in the long cycles above 16 years.

It is worth noting that the results in Figs. 13 and 14 for exports can give no direct indication of any J-curve effects because there are no prices or exchange rates in our analysis. But we can infer that our results are consistent with the Marshall-Lerner conditions being more or less satisfied because the long run correlations are never significant, signifying all price and exchange rate effects have eventually been matched up equally in $\mathrm{C}$ and $\mathrm{X}$-after $\mathrm{C}$ having initially fallen and then risen at the business cycle frequencies. That suggests the price elasticity effects on their own sum to about one. More to the point perhaps, I shows positive correlations overall with $\mathrm{X}$ with leads of 4-16 quarters. It would appear the US invests to export.

In Fig. 13 (lower row, left hand plot) the contemporaneous wavelet correlation plot between investment and government spending shows that $\mathrm{d} 1$ to $\mathrm{d} 3$ exhibit significant correlations with all these correlations negative for up to 8 year cycles. That suggests significant crowding out effects in the short to medium term. But when we look at co-correlations in Fig. 14 (again, lower row, left hand plot), a similar relationship between $I$ and $G$ emerges as between $C$ and $G$ with all wavelet correlation coefficients being positive. At higher frequencies, $\mathrm{d} 2$, I leads $\mathrm{G}$ by up to 8 quarters with a negative correlation (suggesting that some anticipated crowding out effects are operating); but also lags $\mathrm{G}$ with positive correlations at 2 quarters and then negative correlations at 12 quarters (suggesting an immediate stimulus effect, followed by crowding out). At lower frequencies there are no co-correlation effects, so the longer term effects are contemporaneous and somewhat negative-implying that crowding out tends to win out overall (after 4-8 years). What is interesting therefore, is that the conventional crowding out idea beloved of macroeconomic texts between government spending and investment does seem to apply eventually. But there are cross currents of stimulus effects in the shorter run, which make the net outcomes unclear and changeable in the short term, and that there are no crowding out or stimulus effects in the long term. So while both arguments about the effects of government spending are probably right at different points of time, they have probably been overstressed in most practical cases. We find a similar pattern of events in the UK results below.

Perhaps most interestingly among the static results, there are clearly indications of significant wavelet correlations between US private investment and exports at business cycle frequencies. The contemporaneous correlations in Fig. 13 (lower row, middle plot) show d1 to $\mathrm{d} 3$ wavelet correlations are all significant and positive. Healthy demand for US X could stimulate I, or US firms could undertake new I in order to take advantage of new markets to give these results. Of course the fact that the US has tended to drive the international business cycle could also create these results, although it should be noted that the results are different from those of US C and X, so it is unlikely. Figure 14 (lower row, middle plot) shows I leading X by 1-2 quarters, for all time horizons of between 3 and 16 years. But at the same time I lags X by 3 or 4 quarters up to the same horizon. So, again there are both anticipatory effects of exports and ex-post effects of increasing exports—as one might expect; it takes time to both gear up for and then exploit a rising trend of exports. 
Lastly, we look at the correlations between US government spending and exports. As Fig. 13 (lower row, right plot) shows, high frequency cycles are positively contemporaneously correlated, but then from roughly a four year horizon, these correlations turn negative and insignificant. Here the relationship between these two components is more indirect, as government spending can either stimulate exports through the international business cycle and its effects on consumption and investment, or increased exports can increase tax revenues (through increased employment and corporate taxes) resulting in increased government expenditures. In the former case $\mathrm{G}$ should lead $\mathrm{X}$ and in the latter case $G$ should lag X. Figure 14 (lower row, right plot) shows that $G$ lags $\mathrm{X}$ by about 4 quarters at shorter cycles, and particularly at the business cycle frequency captured by d3 and d4, but it also leads $\mathrm{X}$ by about a year. At longer cycles the relationship appears much more complex, with $\mathrm{d} 4$ showing a negative and significant correlation with a one year lead in G over X and then no relationship in $\mathrm{d} 5$ or $\mathrm{d} 6$.

\subsection{UK}

Now we repeat the same exercise with the UK data to see if any common features emerge. In Fig. 15, the contemporaneous correlations are significant and positive between $\mathrm{C}$ and $\mathrm{I}$ for cycles from 1 to 16 years; between $\mathrm{C}$ and $\mathrm{X}$ for 1 year; and between $\mathrm{I}$ and $\mathrm{X}$ for $2-4$ years. But they are negative and significant between $\mathrm{G}$ and $\mathrm{X}$ for $4-8$ years. $\mathrm{C}$ and $\mathrm{G}$, and $\mathrm{I}$ and $\mathrm{G}$, have no contemporaneous movements. Taken together, this suggests that UK consumption and investment move pretty much in step for all but the longest cycles; while consumption and exports do not move together very much, and investment-exports have a limited immediate business cycle relationship. But there may be significant crowding out effects. All of this is fairly standard.

Thus, using Figs. 15 and 16 together, compared to the US, the the picture is rather different. Government expenditures have little common effect on consumption at any lead or lag, or perhaps indirectly only in that consumption rises with investment contemporaneously. But even there consumption switches in and out as investment falls or rises at 2 year leads and lags (ie they are complements immediately, but substitutes at both leads and lags of 8-10 quarters in the business cycles frequencies).

The pattern for contemporaneous correlations between UK consumption and exports is, unlike the US, rather simple as Fig. 15 shows. There is positive correlation for periods on one year, then nothing. But the co-correlations in Fig. 16 shows the relationship is more complicated. In the short cycles, up to 4 years, $C$ lags $X$ by 8 quarters but leads $\mathrm{X}$ at 4 and 10 quarters. So once again, there are cross currents: increased export earnings quickly lead to higher consumption, but at the same time the higher investment/greater competitiveness that allows the extra consumption will also induce extra exports as we saw in the US case. Thus UK consumption helps drive world growth. But, as in the US, these lead and lag effects eventually merge and become unclear in the long cycles above 16 years.

Unlike in the US, for the UK Fig. 15 shows that there are no significant contemporaneous wavelet correlations for I with $\mathrm{G}$, but also that there are no significant co-correlations, as Fig. 16 shows. Interestingly, at short cycles (in particular d2 which corresponds to 2-4 year cycles) all co-correlations are negative, implying that in the 

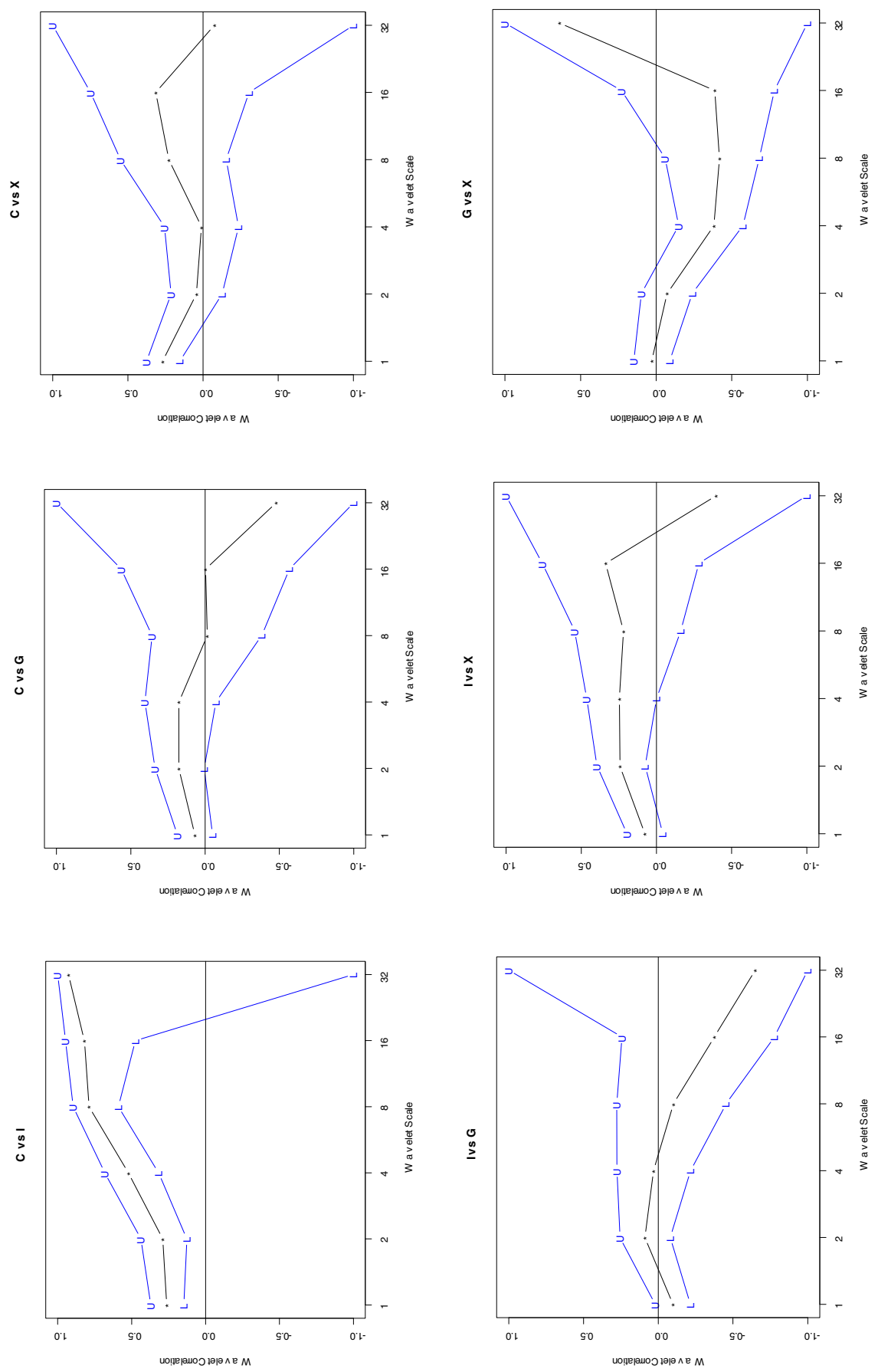

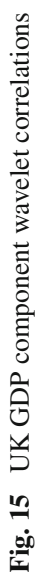



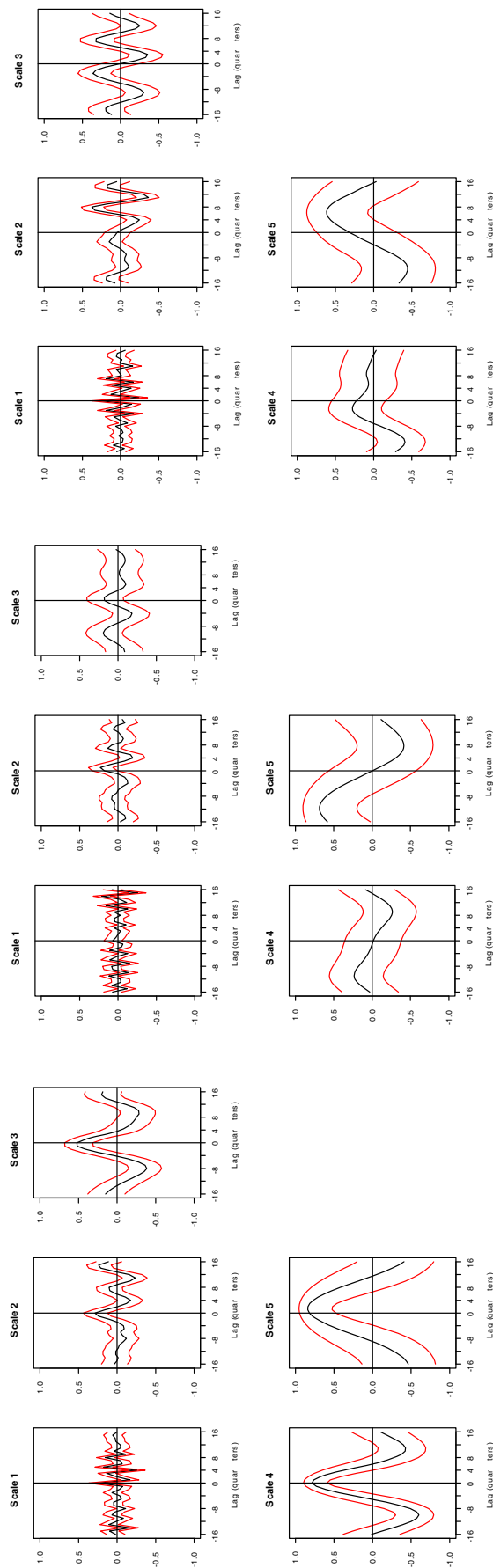
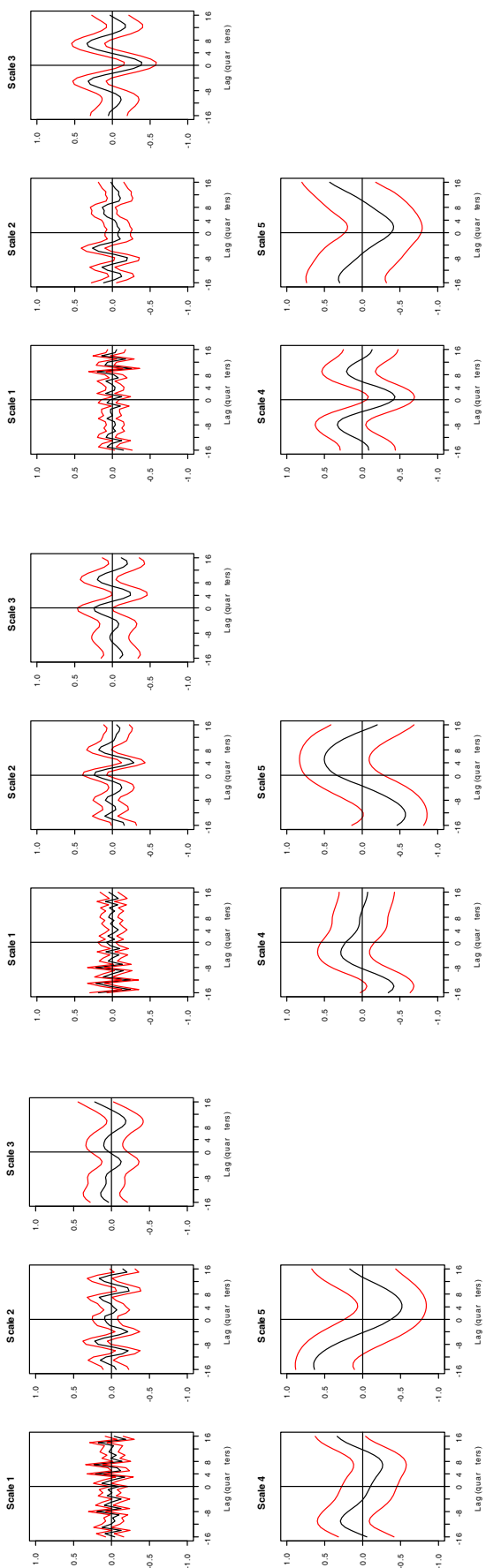

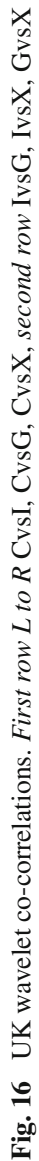


short-term there appears to be a crowding-out effect at work. UK fiscal policy is all current expenditure based therefore, and has little to do with investment stimuluswhether public or private.

But unlike the US, the co-correlations of I with $\mathrm{X}$ are negative in the short cycles with lags of 4 quarters, but positive with a 1 quarter lag. Exports therefore first drive investment and then reduce it as it gets crowded out by consumption.

Lastly, contemporaneous correlations of UK government spending vs exports shown in Fig. 15 gives some unexpected results. Here d3 and d4 (representing 28 year cycles) are negative and significant. This could represent a J-curve effect as recessions usually cause the British currency to depreciate, which could then give rise to government spending being negatively related to exports, although it would be anticipated that this effect would occur at a shorter horizon than 2-8 years. When looking at co-correlations in Fig. 16 it is clear that only in $\mathrm{d} 2-\mathrm{d} 4$ are there any significant co-correlations, and the most signifcant co-correlations are clearly in the 2-4 year cycles, which could well correspond to a crowding out effect as there is a negative and significant co-correlation for $\mathrm{G}$ leading $\mathrm{X}$ by roughly a year.

\section{Conclusions}

This paper shows that the cyclical components of aggregate demand are not negligible, as might be presumed by the proponents of current macroeconomic thinking. Indeed, as in the accelerator mechanism of Keynesian macroeconomic theory, the closest association lies between consumption and investment, and although this occurs at business cycle frequencies there is evidence provided by this paper that there are significant and coherent cycles linking the GDP components at other frequencies.

One of the major results of this paper is that the cyclical relationships between the macroeconomic components of GDP clearly differ by country, with apparently much stronger relationships between components in the US than in the UK, and in particular between consumption and investment.

Another important result found in this paper is that mere contemporaneous correlations do not capture the rich dynamics of the interactions between the GDP components, particularly in terms of the phasing of relationships between them. This is a result found also in other contexts, for example in Chaplygin et al. (2006) for the former Soviet Union economies. But it is the first time that it has been found and emphasized as an important feature of the leading OECD economies.

Further research could focus on (i) the interaction between individual GDP components across countries; (ii) the flow of causation between the GDP components across frequencies; and (iii) a time-varying analysis of the different cyclical elements in GDP and the relations between them; and how shifts in policy rules or the structure of the economy can transfer volatility or "power" from one cycle length to another. The second would clearly be a simple extension of the results presented here, and the latter would entail using causality analysis. The third is perhaps the most interesting for its potential insights into an economy's stability and the policy implications for that economy's stabilisability. Not an easy task; but a start has been made in that direction in Crowley and Hughes Hallett (2014b). 


\section{References}

Bruce A, Gao H-Y (1996) Applied wavelet analysis with S-plus. Springer, New York

Chaplygin V, Hughes Hallett A, Richter C (2006) Monetary integration in the ex-soviet union: a "union of four"? Econ Transit 14(1):47-68

Constantine W, Percival D (2003) S+Wavelets 2.0

Crowley P (2007) A guide to wavelets for economists. J Econ Surv 21(2):207-267

Crowley P, Hughes Hallett A (2014a) The great moderation under the microscope: decomposition of macroeconomic cycles in US and UK aggregate demand. In: Dynamic modeling and econometrics in economics and finance, vol. 20. Wavelet applications in economics and finance, vol. 3, pp. 47-71. Springer International Publishing, Switzerland

Crowley P, Hughes Hallett A (2014b) Volatility transfers between cycles: a theory of why the "great moderation" was more mirage than moderation. Bank of Finland Discussion Paper 23/2014

Crowley P, Hughes Hallett A (2015) Great moderation or 'Will o the Wisp'? A time-frequency decomposition of GDP for the US and UK. J Macroecon (forthcoming)

Crowley P, Lee J (2005) Decomposing the co-movement of the business cycle: a time-frequency analysis of growth cycles in the euro area. Bank of Finland Discussion Paper 12/05, Helsinki, Finland

Gallegati M, Gallegati M (2007) Wavelet variance analysis of output in G-7 countries. Stud Nonlinear Dyn Econ 11(3): 1435-1455

Gençay R, Selçuk F, Whicher B (2001) An introduction to wavelets and other filtering methods in finance and economics. Academic Press, San Diego

Greenhall C (1991) Recipes for degrees of freedom of frequency stability estimators. IEEE Trans Instrum Meas 40:994-999

Percival D, Mofjeld H (1997) Analysis of subtidal coastal sea level fluctuations using wavelets. J Am Stat Assoc 92:868-880

Percival D, Walden A (2000) Wavelet methods for time series analysis. Cambridge University Press, Cambridge

Ramsey J (2008) Wavelets. In: Durlauf S, Blume L, editors. The new Palgrave dictionary of economics, 2nd edn. Palgrave Macmillan, Basingstoke

Ramsey J, Lampart C (1997) The decomposition of economic relationships by time scale 97-08

Shensa M (1992) The discrete wavelet transform: wedding the à trous and mallat algorithms. IEEE Trans Signal Process 40:2464-2482

Walden A, Cristan C (1998) The phase-corrected undecimated discrete wavelet packet transform and its application to interpreting the timing of events. Proc R Soc Lond Math Phys Eng Sci 454(1976):22432266

Whitcher B, Guttorp P, Percival D (1999) Mathematical background for wavelet estimators of crosscovariance and cross-correlation. Technical Report TSE No. 038, NRCSE

Whitcher B, Guttorp P, Percival D (2000) Wavelet analysis of covariance with application to atmospheric time series. J Geophys Res 105(D11):14941-14962

Yogo M (2008) Measuring business cycles: a wavelet analysis of economic time series. Econ Lett $100(2): 208-212$ 